\title{
PENGARUH PEMBERIAN SAFETY TALK TERHADAP KEPATUHAN PENGGUNAAN ALAT PELINDUNG DIRI (APD) PADA PEKERJA BATU BATA
}

\author{
Anggi Isnani Parinduri ${ }^{1}$, Irmayani ${ }^{2}$, Rosita Ginting ${ }^{3}$, Ismail Sirait ${ }^{4}$ \\ Institut Kesehatan Medistra Lubuk Pakam \\ Jl. Sudirman No. 38 Lubuk Pakam Kec. Lubuk Pakam Kab. Deli Serdang, \\ Sumatera Utara \\ Email: anggisnani@gmail.com
}

\begin{abstract}
The level of achievement of Occupational Health and Safety (OHS) implementation in brick factories in Indonesia is very low. One of the ways to implement OHS is by conducting safety talk. giving of safety behavior materials is expected to make workers obedient to the use of PPE and increase workers knowledge about PPE. This research was a quantitative study with a quasiexperimental, quasi-experimental approach to the research design using pretest and post-test. Determination of the number of samples used the purposive sampling method and obtained a sample of 34 workers. The Data collection was carried out by interviewed using a questionnaire and observation sheet. The independent variable in this study was safety talk while the dependent variable is compliance with the use of Personal Protective Equipment (PPE). Evaluation of Compliance with the use of PPE is in the compliance category (55.9\%). Statistical tests used the Wilcoxon Signed Rank Test with $a=0.05$. The results of the analysis showed that there was an effect of providing safety talk on obedience with the use of PPE on brick workers in Sidourip Village, Beringin District in 2020, namely (0.002 $\leq 0.05)$. The conclusion of this study was that there is an influence between safety talk with obedience with the use of PPE. The advice that can be given is that every brick worker must use PPE and attend safety talk activities.
\end{abstract}

\section{Keywords : Safety Talk, Compliance, Personal Protective Equipment, Workers}




\section{PENDAhuluan}

International

Labour

Organization (ILO) menuturkan bahwa dari 15.017 perusahaan hanya sekitar $317(2 \%)$ perusahaan yang telah mengimplementasikan program keselamatan dan kesehatan kerja (K3) dengan cukup baik, selebihnya sekitar $14.700(98 \%)$ perusahaan belum sama sekali mengimplementasikan program $\mathrm{K} 3$ secara baik. Indonesia memiliki angka kecelakaan yang cukup tinggi. Pada tahun 2017 kasus mencapai 105.383 dengan cacat fungsi sebanyak 3.618 kasus, cacat sebagian sebanyak 2.616 kasus, cacat total sebanyak 43 kasus, dan meninggal sebanyak 2.375 kasus. Pada akhir tahun 2018 telah terjadi kecelakaan kerja sejumlah 105.182 kasus dengan korban meninggal dunia sebanyak 2.375 orang (Badan Penyelenggara Jaminan Sosial Ketenagakerjaan, 2018).

Berbagai upaya dilakukan untuk meningkatkan aspek $\mathrm{K} 3$ diantaranya dengan upaya Safety Promotion dalam bentuk komunikasi K3. Upaya yang dapat dilakukan untuk mencegah terjadinya kecelakaan kerja, salah satunya adalah dengan komunikasi K3. Berbagai contoh upaya Safety Promotion adalah safety sign, safety induction, dan safety talk (Primadana, 2016). Safety Talk sangat tepat dilakukan oleh orang-orang yang bertanggung jawab akan keselamatan dan kesehatan kerja seperti supervisor, safety officer, anggota safety commite (Bennet, 2018).

Safety talk merupakan salah satu bentuk komunikasi K3 dimana dilaksanakan oleh manusia dengan manusia secara langsung (Ramli, 2017). Proses kegiatan dari safety talk ini yaitu dengan cara memberikan materi ataupun pendidikan terkait perilaku selamat yang dimana harapannya bisa memperluas pengetahuan serta menciptakan kesadaran kepada tenaga kerja untuk merubah perilaku unsafe act menjadi safe act. Kesadaran akan manfaat penggunaan APD perlu ditanamkan pada setiap tenaga kerja, karena perasaan tidak nyaman (risih, panas, berat, terganggu) adalah alasan pekerja tidak menggunakan APD. Pembinaan yang berkesinambungan dan berkelanjutan dapat meningkatkan kesadaran dan wawasan pekerja, salah satu cara yang efektif adalah melalui pelatihan. Peningkatan pengetahuan dan wawasan akan menyadarkan tentang pentingnya penggunaan APD, sehingga efektif dan benar dalam penggunaannya (Budiono, 2017).

Hasil penelitian yang telah dilakukan Nasrullah pada tahun 2014 menyebutkan bahwa tenaga kerja yang mendapatkan program safety talk yang baik tentunya memiliki pengetahuan serta perilaku yang lebih baik. Walaupun program safety talk terbukti bisa mempengaruhi pengetahuan dan perilaku aman para tenaga kerja, namun kenyataannya masih juga ditemukan unsafe act pada tenaga kerja. Hasil penelitian Sari tahun 2016 mengenai efektivitas komunikasi safety talk sebagai pemenuhan informasi K3 bagi pekerja di PT. Multikom menunjukkan bahwa dengan program Safety Talk sebelum bekerja sangat efektif dalam pemenuhan kebutuhan informasi mengenai $\mathrm{K} 3$ serta dapat membangun kesadaran pekerja untuk mengutamakan keselamatan dalam pencegahan terjadinya kecelakaan kerja.

\section{METODE PENELITIAN}

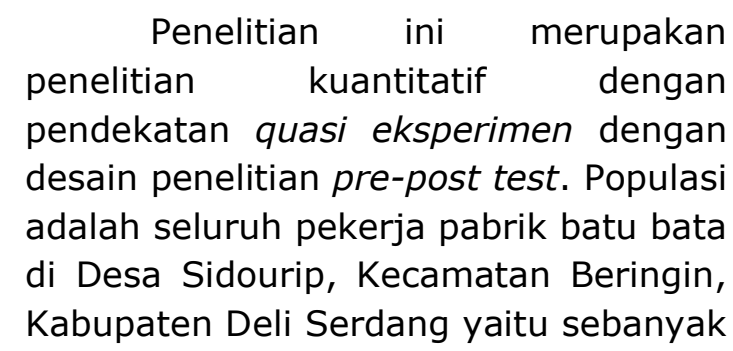


74 orang. Pengambilan sampel dengan menggunakan teknik purposive sampling, sehingga yang menjadi responden berjumlah 34 orang. Pengumpulan data dengan menggunakan data primer dan data sekunder. Lembar Observasi dilakukan kepada responden dengan berpedoman pada lembar observasi yang telah dipersiapkan merupakan teknik yang digunakan dalam mengumpulkan data primer, sedangkan data sekunder diperoleh dari kantor Kepala Desa Dusun 1A Sidourip, Kecamatan Beringin, Kabupaten Deli Serdang yaitu data terkait jumlah masyarakat yang memiliki pekerjaan sebagai pembuatan batu bata. Setelah data terkumpul. Kemudian diolah dengan menggunakan uji Wilcoxon Sign Rank Test dengan tingkat kepercayaan 95\% (alpha=5\%). Dasar pengambilan keputusan dengan ketentuan jika nilai $\mathrm{p}<\mathrm{a}$ maka Ho ditolak yang dapat disimpulkan bahwa terdapat hubungan antara variabel independen dengan dependen.

\section{HASIL}

Tabel 1. Distribusi Responden Berdasarakan Karakteristik Pekerja

\begin{tabular}{|c|c|c|}
\hline Karakteristik & f & $\%$ \\
\hline \multicolumn{3}{|l|}{ Usia } \\
\hline$\leq 25$ Tahun & 8 & 23,6 \\
\hline$\geq 25$ Tahun & 26 & 76,4 \\
\hline Total & 34 & 100 \\
\hline \multicolumn{3}{|l|}{ Pendidikan } \\
\hline SD & 2 & 5,9 \\
\hline SMP & 20 & 58,8 \\
\hline SMA & 12 & 35,3 \\
\hline Total & 34 & 100 \\
\hline
\end{tabular}

Tabel 1 menunjukkan jumlah responden dalam penelitian ini sebanyak 34 orang. Mayoritas responden berumur $>25$ tahun sebanyak 26 orang $(76,4 \%)$ dan tingkat pendidikan SMP sebanyak 20 orang $(58,8 \%)$.
Tabel 2. Distribusi Frekuensi Responden Berdasarkan Tingkat Kepatuhan Penggunaan Alat Pelindung Diri (APD) Sebelum Diberikan Safety Talk

\begin{tabular}{lcc}
\hline $\begin{array}{c}\text { Tingkat } \\
\text { Kepatuhan }\end{array}$ & \multicolumn{2}{c}{$\begin{array}{c}\text { Kelompok } \\
\text { Perlakuan } \\
\text { Pre Test } \\
\text { f }\end{array}$} \\
\hline Patuh & 9 & 26,5 \\
Tidak Patuh & 25 & 73,5 \\
\hline Total & $\mathbf{3 4}$ & $\mathbf{1 0 0}$ \\
\hline
\end{tabular}

Tabel 2 menunjukkan jumlah dan persentase responden berdasarkan tingkat kepatuhan sebelum dilakukan intervensi berupa Safety Talk, pada kelompok perlakuan terdapat 25 orang $(73,5 \%)$ yang tidak patuh dan 9 orang $(26,5 \%)$ yang patuh.

Tabel 3. Distribusi Frekuensi Responden Berdasarkan Tingkat Kepatuhan Penggunaan Alat Pelindung Diri (APD) Sesudah Diberikan Safety Talk

\begin{tabular}{lcc}
\hline $\begin{array}{c}\text { Tingkat } \\
\text { Kepatuhan }\end{array}$ & \multicolumn{2}{c}{$\begin{array}{c}\text { Kelompok } \\
\text { Perlakuan } \\
\text { Post Test } \\
\text { for }\end{array}$} \\
\hline Patuh & 19 & 55,9 \\
Tidak Patuh & 15 & 44,1 \\
\hline Total & $\mathbf{3 4}$ & $\mathbf{1 0 0}$ \\
\hline
\end{tabular}

Tabel 3 menunjukkan jumlah dan persentase responden berdasarkan tingkat kepatuhan sesudah dilakukan intervensi berupa Safety Talk, pada kelompok perlakuan terdapat 15 orang $(44,1 \%)$ yang tidak patuh dan 19 orang $(55,9 \%)$ yang patuh.

Tabel 4. Rerata Kepatuhan Penggunaan APD Sebelum dan Sesudah Diberikan Safety Talk

\begin{tabular}{llll}
\hline $\begin{array}{c}\text { Kepatuhan } \\
\text { Penggunaan } \\
\text { APD }\end{array}$ & Mean & SD & p.value \\
\hline Sebelum & 2,35 & 1,276 & \\
& & & \\
& &
\end{tabular}




\begin{tabular}{llll} 
Sesudah & 3,06 & 1,179 & 0,002 \\
Selisih & 0,71 & 0,097 & \\
\hline
\end{tabular}

Tabel 4 menunjukkan bahwa rerata kepatuhan penggunaa APD sebelum diberikan Safety Talk yaitu 2,35 dengan standar deviasi sebesar 1,276 sedangkan skor rerata kepatuhan penggunaa APD sesudah diberikan Safety Talk yaitu 3,06 dengan standar deviasi sebesar 1,179. Selisih rata-rata sebelum dan sesudah pemberian Safety Talk yaitu 0,71 dengan standar deviasi sebesar 0,097.

\section{PEMBAHASAN}

Berdasarkan hasil penelitian yang dilakukan pada 34 pekerja pembuat batu bata pada penilaian kepatuhan penggunaan APD dengan menggunakan lembar observasi sebelum dilakukan intervensi, pada kelompok perlakuan terdapat 25 responden $(73,5 \%)$ memiliki tingkat kepatuhan yang tidak patuh dan 9 responden (26,5\%) memiliki tingkat kepatuhan yang patuh. Rata-rata tingkat kepatuhan penggunaan APD sebelum di berikan Safety Talk yaitu mean $=2,35$ dan standar deviasi sebesar 1,276.

Berdasarkan hasil penelitian yang dilakukan pada 34 pekerja pembuat batu bata pada penilaian kepatuhan penggunaan APD dengan menggunakan lembar observasi sesudah dilakukan intervensi, pada kelompok perlakuan terdapat 15 orang $(44,1 \%)$ yang tidak patuh dan 19 orang $(55,9 \%)$ yang patuh. Rata-rata tingkat kepatuhan penggunaan APD sesudah di berikan Safety Talk yaitu mean $=3,06$ dan standar deviasi sebesar 1,179.

Menurut Nasrullah (2014) dalam penelitiannya mengemukakan bahwa pekerja yang mendapatkan safety talk yang baik akan memiliki pengetahuan dan attitude safe behavior yang lebih baik. Meskipun safety talk terbukti dapat mempengaruhi pengetahuan dan perilaku aman pekerja, pada kenyataannya masih saja dijumpai unsafe act pada pekerja. Tindakan tidak aman pekerja diantaranya adalah kurang patuhnya pekerja terhadap pemakaian Alat Pelindung Diri (APD) pada saat bekerja.

Berdasarkan hasil uji statistik dengan menggunakan Uji Wilcoxon Signed Rank Test menunjukkan bahwa $\mathrm{p}$ Value $(0,002) \leq \mathrm{a}(0,05)$, yang berarti ada pengaruh pemberian Safety Talk terhadap kepatuhan penggunaan APD pada pekerja batu bata di desa sidourip kecamatan beringin tahun 2020. Hasil Penelitian ini sejalan dengan penelitian Gumelar (2016) diperoleh hasil bahwa Program Safety Talk yang diberikan perusahaan dinilai oleh $85,1 \%$ responden dalam kategori efektif. Tingkat pengetahuan tentang APD yang dimiliki oleh $89,6 \%$ responden sudah baik dan $56,7 \%$ responden memiliki kepatuhan yang positif terhadap penggunaan APD. Uji statistik safety talk dengan pengetahuan menggunakan pearson chi-square menunjukkan terdapat hubungan antara safety talk dengan tingkat pengetahuan yaitu $(p=0,001)$. Komponen kepatuhan di uji dengan uji yang sama dan menunjukkan hasil adanya hubungan antara safety talk dengan kepatuhan penggunaan APD. Kesimpulan dari penelitian ini adalah Terdapat hubungan antara safety talk dengan kepatuhan penggunaan APD dan terdapat hubungan antara safety talk dengan tingkat pengetahuan tentang APD.

\section{KESIMPULAN}

Kesimpulan pada penelitian ini yaitu:

1) Karakteristik responden berdasarkan umur dan tingkat pendidikan yaitu dari 34 orang responden terdapat pekerja yang berusia $\geq 25$ tahun sebanyak 26 orang, sedangkan 
pekerja dengan tingkat pendidikan SMP sebanyak 20 orang.

2) Tingkat Kepatuhan penggunaan alat pelindung diri (APD) pada pekerja batu bata, dari 34 orang responden sebelum diberikan Safety Talk didapatkan bahwa pekerja yang patuh sebanyak 9 orang (26,5\%) dan setelah diberikan Safety Talk mengalami peningkatan yang signifikan yaitu sebanyak 19 orang (55,9\%).

3) Ada pengaruh pemberian Safety Talk terhadap kepatuhan penggunaan alat pelindung diri (APD) pada pekerja batu bata di Desa Sidourip Kecamatan Beringin Tahun 2020 dengan $p(0,002) \leq a(0,05)$.

\section{DAFTAR PUSTAKA}

Badan Penyelenggara Jaminan Sosial Ketenagakerjaan. 2018. Angka Kecelakaan Kerja Karyawan di Indonesia Tahun 2016 - 2018. Jakarta

Bennet N.B. Silalahi. 2018. Manajemen Keselamatan dan Kesehatan Kerja. Jakarta: PT. Binaman Pressindo.

Budiono. 2017. Hiperkes dan Kesehatan Kerja, Semarang : Badan Penerbit Universitas Diponegoro.

Cooper, D. 2016. Behavioral Safety A Framework for Succes. Indiana. BSMS Inc.

Gumelar, Fajar. 2018. Hubungan Safety Talk dengan Tingkat Pengetahuan dan Kepatuhan Penggunaan Alat Pelindung Diri (Studi di Unit Maintenance PT Holcim Indonesia Tbk). Surabaya: Fakultas Kesehatan Masyarakat Universitas Airlangga

International Labour Organization (ILO.2017). Data Kecelakaan Kerja Pada Pekerja Kontruksi. Diakses pada tanggal 12 November 2019

Lemeshow, S., Hosmer, D.W., Klar, J \& Lwanga,S.K. 1997. Besar Sampel Dalam Penelitian Kesehatan.
Jogjakarta: Gajahmada university press

Notoadmojo. 2014. Metodologi Penelitian Kesehatan. Jakarta. Rieneka Cipta

Primadana, Try Sadewo. 2016. Analisis Efek tifitas Implementasi Safety Promotion pada Pekerja di PT. Lautan Otsuka Chemical Tahun 2012. Jakarta. Universitas Indonesia.

Ramli, S. 2017. Smart Safety, Panduan penerapan SMK3 yang Efektif. Jakarta: Dian Rakyat

Sari. 2016. Efektivitas Komunikasi Safety Talk Sebagai Pemenuhan Informasi K3 Bagi Karyawan PT. Multikon. Jakarta: Universitas Mercubuana

Sugiyono. 2014. Statistika Untuk Penelitian, Bandung, Alfabeta. 